\title{
Inductive Metaphysics
}

\section{Editors' Introduction}

\author{
Kristina Engelhard \\ Universität Trier, Trier, Germany \\ engelhard@uni-trier.de
}

Christian J. Feldbacher-Escamilla | ORCID: 0000-0001-6414-2153

Düsseldorf Center for Logic and Philosophy of Science (DCLPS), University of Düsseldorf, Düsseldorf, Germany

cj.feldbacher.escamilla@gmail.com
Alexander Gebharter | ORCID: 0000-0003-1708-2949
Munich Center for Mathematical Philosophy (MсмP),
Ludwig-Maximilians-Universität München, München, Germany alexander.gebharter@gmail.com

\author{
Ansgar Seide \\ Westfälische Wilhelms-Universität Münster, Münster, Germany \\ ansgar.seide@uni-muenster.de
}

\begin{abstract}
This introduction consists of two parts. In the first part, the special issue editors introduce inductive metaphysics from a historical as well as from a systematic point of view and discuss what distinguishes it from other modern approaches to metaphysics. In the second part, they give a brief summary of the individual articles in this special issue.
\end{abstract}

\section{Keywords}

inductive metaphysics - trans-disciplinarity - sources of knowledge - abduction meta-metaphysics 
There seems to be scarcely any other philosophical discipline that has received such contrary appraisal as metaphysics. It was traditionally considered to be "the queen of all the sciences" (CPR, A VIII $)^{1}$, while logical positivism and logical empiricism, for example, considered it to be the poor cousin of philosophy. But also, among those philosophers who have a high esteem for metaphysics, there are diametrically opposed views on what its subject matter is and on what methods can and should be used to achieve metaphysical knowledge. Such wide disagreement cannot only be found in the history of philosophy, we find it also in contemporary discussions. E.J. Lowe (2011) and Kit Fine (2012), for instance, plead for a purely aprioristic account of metaphysics, whereas James Ladyman and Don Ross (2007) as well as Tim Maudlin (2007) argue for the elimination of metaphysics as an independent philosophical discipline and for its dissolution into the particular sciences. Both accounts are extremes: the former denies empirical or a posteriori reasoning any methodological role in metaphysics, while the latter does the same for purely a priori reasoning.

Inductive metaphysics can be considered to be an approach which is a moderate position between these two extremes. It lifts the aprioristic constraint by stressing the role of empirical sources and methodology for metaphysical investigations: scientific data and theories, everyday experience, and the inductive as well as abductive methodology of natural science are considered to be essential parts of the metaphysician's toolbox. At the same time, it also lifts the eliminativist constraint by stressing the role of aprioristic tools for metaphysics: metaphysics' trans-disciplinary character - which consists in the generalisation and unification of concepts, principles, and even whole theories of single disciplines to abstract and overarching concepts, principles, and theories - asks also for the application of aprioristic methods such as conceptual analysis.

This introduction and the contributions of this volume aim at characterising the programme of inductive metaphysics and delineate its tradition, wide range of applications to metaphysical issues, but also its open questions and problems. For this purpose, we start in section 1.1 with an outline of distinctive features of inductive metaphysics, namely the implementation of empirical sources of knowledge and an empirical methodology. In section 1.2, we describe the historical tradition of this approach. In section 1.3, we characterise

1 The Critique of Pure Reason is cited with the abbreviation " $C P R$ ", followed by the page number of the first, 1781 edition ("A"). (The quoted phrase does not occur in the B edition.) The translation is from the Cambridge edition (Kant 1998). 
the epistemic sources of inductive metaphysics in more detail and in section 1.4 its methodology. Section 1.5 concludes with a brief discussion of important problems and urgent questions of this approach. Finally, in section 2, we provide an overview of the contributions of this volume.

\subsection{From Traditional to Inductive Metaphysics: A First Glimpse}

Throughout the history of philosophy, metaphysics has repeatedly been subject to the criticism that, given the nature of the objects to which it supposedly refers, it is not capable of justifying its claims. At the beginning of the 2oth century, it was logical positivism that aggressively attacked metaphysics. As a result of this attack, metaphysics was hardly considered a serious project in analytic philosophy in the early and mid-2oth century. However, two developments within the analytic tradition resulted in a resurrection of metaphysics in the second half of the 2oth century: First, some philosophers started to aim for a more direct relationship between philosophy and science. A first branch starting with Quine focused on the idea that science is committed to certain ontologies, that is theories about which kinds of entities there are and how to correctly understand the term "existence". Debates on ontological commitments of scientific theories led to a new naturalistic form of metaphysics. Second, the development of modal logic beginning with Saul Kripke's modal semantics paved the way to investigate metaphysical issues in terms of possible worlds and many analytic philosophers soon realised that at least some metaphysical questions are an indispensable part of philosophy.

Metaphysical knowledge is supposed to be knowledge of a certain domain of objects. The main problem of traditional metaphysics is linked to the problem of answering two fundamental questions:

- What exactly is the domain of metaphysics?

- How can we gain knowledge about this domain?

In Aristotle's writings, we find four different determinations of the object of metaphysics: it is the doctrine (1) of that which exists insofar as it exists - that is, of the most general characteristics of all that exists -, (2) of the first causes or principles of that which exists, (3) of the essences of that which exists, and, finally, (4) of the divine (cf., for example, Reale 1980, 1-3). Aristotle was also one of the first to claim that a specific kind of cognition is necessary for these objects. In post-Aristotelian philosophy, his ideas have been developed into a variety of special metaphysical forms of knowledge. In early modern thought, advances in mathematics and the experimental method led to a reassessment of metaphysics: On the one hand, this resulted in a demarcation between physics and metaphysics concerning the objects of enquiry. According to Francis Bacon, for example, physics explores the efficient and material causes 
of objects, while metaphysics deals with the formal and final causes. On the other hand, mathematics was advancing to become a model and basic science. The analytic-synthetic method which Pappos extracted from Euclid's Elementa and which we can translate as the inductive-deductive method, was made the exemplary method for all sciences. Descartes' endeavour was to erect a deductive system on the basis of evident principles. In Leibniz the clarification of concepts and the deduction of further metaphysical truths out of these principles plays a predominant role in metaphysical investigations. However, the role of experience and inductive methods has always been a complementary part of the discipline as, for example, the metaphysics of Wolff shows (Engelhard 2021, this volume). Kant was the first who simplified the much differentiated epistemological and metaphysical theories and methodologies by stipulating that metaphysics is a science that is independent of experience, that is a priori, because the objects of its investigation transcend experience ${ }^{2}$ (Prol, AA 4: 265 f.; emphasis in the original): ${ }^{3}$

[C]oncerning the sources of metaphysical cognition, it already lies in the concept of metaphysics that they cannot be empirical. The principles of such cognition (which include not only its fundamental propositions, but also its fundamental concepts) must therefore never be taken from experience; for the cognition is supposed to be not physical but metaphysical, i.e., lying beyond experience. [...] It is therefore cognition a priori, or from pure understanding and pure reason.

In the history of philosophy, numerous arguments have been put forward for the view that the human cognitive capacities are such that they are unable to achieve this kind of knowledge in the domain of metaphysics. This raises the question whether we can have knowledge about the existence of objects as assumed by metaphysics at all. The questions metaphysics deals with might even be - as logical positivists claimed - merely pseudo-problems arising from an erroneous understanding of language.

However, there are alternative approaches to such a form of scepticism. For example, a completely different perspective on metaphysics opens up if one

2 As Seide (2020, ch. 4.2 and ch. 6.4.6; forthcoming-a) argues, it can be shown that Kant himself still allows for at least some empirical elements in his metaphysics of nature.

3 The Prolegomena to Any Future Metaphysics That Will Be Able to Come Forward as Science is cited with the abbreviation "Prol", followed by the volume (4) and page number from the Akademie edition (I. Kant, Gesammelte Werke, ed. königlich preußische Akademie der Wissenschaften (und Nachfolger), Berlin 1900 f.). The translation is from the Cambridge edition (Kant 2002). 
gives up the assumption that metaphysical knowledge has to be knowledge a priori. Rather, one might assume that experience can play an important role in metaphysical theory formation and justification. It is particularly this approach that is taken up and developed by the advocates of inductive metaphysics from the mid-19th to the early 2oth century. Among others, Gustav Theodor Fechner (1801-1887), Rudolph Hermann Lotze (1817-1881), Oswald Külpe (1862-1915), Eduard von Hartmann (1842-1906), Wilhelm Wundt (1832-1920) and Erich Becher (1882-1929) hold that experience is relevant for metaphysics in the sense that experience importantly factors into the construction and justification of metaphysical theories. Furthermore, inductive metaphysics also claims that inductive methods in the wide sense (that is any form of non-deductive ampliative reasoning - cf. Schurz 2021, sect.1, this volume) that were proven to be successful in natural science are also essential for justifying metaphysical theories. At least the first three Aristotelian determinations of the domain of metaphysics do not exclude that the objects of metaphysics are related to experience. Therefore, while the idea of an inductive metaphysics does not necessarily break with classical approaches to metaphysics, it is clearly opposed to Kant's definition of metaphysics in terms of a priori knowledge.

Inductive metaphysics addresses the positivist challenge by way of adopting a scientific attitude itself: it is based on the ideas that (i) metaphysical issues should be answered by taking empirical or scientific information into account and (ii) by using methods that are successfully applied in science. By doing so, metaphysics in the analytic tradition has recently become a discipline with a deeply entrenched naturalistic orientation. Regarding the naturalistic conviction, two further metaphysical approaches, which differ from inductive metaphysics, became highly influential: naturalised metaphysics and the so-called Canberra Plan. According to naturalised metaphysics, metaphysical knowledge can be inferred by the help of methods of science alone. This is done exclusively on the basis of scientific research results. In this approach, the only purpose for achieving metaphysical knowledge is to unify scientific hypotheses and theories that are accepted in contemporary science (cf. Ladyman \& Ross 2007). Naturalised metaphysics aims at integrating metaphysics into the empirical sciences, particularly into physics. In its strong form, it states that questions of metaphysics are directly answered by science and "that it is only by means of scientific results and scientific methods that metaphysical knowledge is possible" (Kincaid 2013, 3). Inductive metaphysics is less restrictive. It recognises that a priori methods such as conceptual analysis are also valuable tools to obtain and illuminate metaphysical hypotheses (for a case study of the relevance of a priori methods within inductive metaphysics cf. Busse 2021, this volume; also Schurz 2021, sect.2, stresses that inductive metaphysics rejects 
only exclusively a priori arguments, but is not opposed to all sorts of a priori reasoning), and that experiential facts that are not the subject any empirical science but which can nevertheless lay claim to objectivity such as everyday experience, folk explanations, and certain kinds of semantic intuitions, are metaphysically relevant (also Bryant 2021, this volume, notes that naturalised metaphysics focusses on scientific evidence only, whereas the sources of evidence of inductive metaphysics are wider). Inductive metaphysics also differs from the Canberra Plan. The main goal of the Canberra Plan is to connect concepts and hence also metaphysical concepts to scientifically proven facts by means of a certain multi-stage process and, thus, to endow metaphysical concepts such as "causality" or "time" with empirical content (cf. Braddon \& Nola 20o9). Typically, Canberra planners start with a metaphysical concept and then look at the sciences and try to find something to which that concept could be applied. In contrast to this, inductive metaphysics proceeds the other way around. It starts with scientific methods and empirical facts and uses them as a basis for gaining metaphysical knowledge. Generally, it deals with structures that underlie the realm of the particular sciences, but are not accessible to the theories of particular sciences as such. It aims to link and bridge several particular fields of science, thereby addressing problems and questions that are not dealt with - at least not in a general way - within any particular science. Inductive metaphysics, for instance, deals with the question what the nature of properties is, whether we should think of them as being categorical or dispositional, on the basis of scientific theories and empirical facts and by inductive methodology. Questions like this are not addressed within any specific empirical science.

Although inductive metaphysics gained increasing attention within the philosophical community only quite recently, it is not (completely) new and has historic precursors. Contemporary investigations in inductive metaphysics often explicate metaphysical methodology that has been practised in the history of philosophy long before the term has been coined for the first time in the late 19th century (cf. Scholz 2018). In this sense, "inductive metaphysics" is a descriptive term for those approaches of metaphysics that proceed along the lines outlined above and which will be characterised in more detail below, also in cases where the respective position does not subscribe to the term explicitly (we think that, for example, the metaphysics of David Armstrong, Alexander Bird or Brian Ellis can be assigned to this account).

Given this general relation between inductive metaphysics and science, experience can play various roles in approaches to inductive metaphysics. Clearly, experience can play an important role in exploratory investigations that aim at formulating metaphysical hypotheses. However, perhaps the most 
fundamental role of the reference to experience and empirical data is to ensure objectivity in some sense, that is that metaphysical claims have reference to the world, that they are not concerned with our conceptual scheme only and that they are not influenced by non-scientific factors, particular perspectives or even ideological convictions. The relation between metaphysics and science in inductive metaphysics is not a clear-cut matter but may take various forms along a spectrum in different accounts. It can restrictively confine metaphysics to explain empirical phenomena or scientific theories, which brings quite strong implications regarding objectivity with it. On a middle ground, inductive metaphysics can aim at using experience to confirm metaphysical hypotheses. A very weak requirement would be that metaphysics does not conflict with our current scientific knowledge. This would have only minimal implications regarding objectivity. However, it is contentious among inductive metaphysicians whether this condition is sufficient.

With regard to its method, inductive metaphysics is distinguished from its a priori opponents by the fact that non-deductive reasoning procedures play a prominent role. Inductive inferences (in the wide sense) are, however, not truth-preserving or monotonic. Hence, their conclusions are not true conditional on the truth of their premises, but only true with a certain degree of probability conditional on the truth of their premises. Therefore, in contrast to traditional aprioristic views of metaphysics, the approach of inductive metaphysics does not claim apodictic certainty for metaphysical knowledge, but pursues the aim of providing metaphysical knowledge that can claim a certain degree of probability. Thus, in comparison to traditional accounts, inductive metaphysics has a much more modest aim.

\subsection{The History of Inductive Metaphysics}

The term "inductive metaphysics" was probably for the first time used by Oswald Külpe (1862-1915) and Eduard von Hartmann (1842-1906) in the late 19 th century. Both were renowned philosophers in Germany at their time (cf. Scholz 2018, $278 \mathrm{ff}$.). However, there were important predecessors of this programme. Particularly Gustav Theodor Fechner (1801-1887), Rudolph Hermann Lotze (1817-1881) and Wilhelm Wundt $\left(183^{2-1920)}\right.$ paved the way for this new conception of metaphysics (cf. Scholz 2018, $276 \mathrm{ff}$ ). A related programme was also advocated by Franz Brentano (1838-1917) (cf. Scholz 2018, 275, n. 34).

Fechner, who can be seen as the initiator of this programme, stated his basic idea of what was later called "inductive metaphysics" in his "Zend-Avesta oder über die Dinge des Himmels und des Jenseits": Metaphysics should be based on the same forms of inference that play a central role in natural science. For Fechner, these forms of inference consist mainly in inductive generalisations 
and analogical reasoning (for the exact role of analogical inference in Fechner's inductive metaphysics cf. Seide 2021, this volume). ${ }^{4}$

Lotze, a disciple of Fechner, follows Fechner in modeling metaphysics according to natural science. In his main work "Mikrokosmus", he states (Lotze 1899, vol. 2, 350):

Thus philosophy takes the same course that we have already seen taken by natural science; it begins with the individual enigmatical and contradictory phaenomena which experience offers, and guided by the general laws of thought seeks to ascertain the form of real existence and occurrence which, in order to explain what is strange and contradictory in facts, must be supposed to underlie these as their efficient cause.

As Lotze puts it here, philosophy should - just like natural science - start its investigations with empirical phenomena and then identify the causes that must be underlying these phenomena in order to explain anomalies and thereby resolve alleged contradictions. Even if Lotze does not use this term, this step can be seen as a kind of abductive inference. (For more on abductive inference and its central role for inductive metaphysics, see below sect. 1.4.)

Wundt also takes the same line of reasoning when describing metaphysics. As he puts it programmatically in his "Logik", the particular sciences should prepare the ground for metaphysics. ${ }^{5}$ In his "System der Philosophie", he highlights three basic features of inductive metaphysics: First, the rejection of an a priori speculative metaphysics, second, the emphasis on an inductive method in metaphysics, modelled after the method of natural science, and third, the trans-disciplinary character of inductive metaphysics, which puts forward as a

4 "Alle Gesetze und Realprincipien der Naturwissenschaften sind bekanntlich auf dem Wege der Induction und Analogie gewonnen, und die Vernunft hat dabei kein anderes Geschäft gehabt, als das freilich sehr wichtige und im bloßen Sinne an sich gar nicht liegende der Verallgemeinerung des Besondern und der widerspruchslosen Combination des von verschiedenen Seiten her gewonnenen Allgemeinen [...]. Nicht anders aber ist es meines Erachtens mit der Wissenschaft aller Existenz überhaupt. Verallgemeinerung durch Induction und Analogie und vernünftige Combination des von verschiedenen Seiten her gewonnenen Allgemeinen sind meines Erachtens die einzigen theoretischen Wege und Weisen, die uns im Gebiete der geistigen wie materiellen Wirklichkeit zu in sich haltbaren und für die Erfahrung wieder fruchtbaren Grundlagen des Wissens über das Selbstverständliche und unmittelbar Gegebene hinaus führen können." (Fechner 1851, vol. I, XXI)

5 "Wir verlangen, dass der Philosophie überall durch die Erfahrungswissenschaften der Boden bereitet werde." (Wundt 1883, 221)

For an analysis of Wundt's "Logik" as a prelude to an inductive metaphysics see Seide (forthcoming-b). 
task of metaphysics the unification of the results of the particular sciences in an overall system. ${ }^{6}$

As stated above, Oswald Külpe was probably the first who characterised this approach as "inductive metaphysics". In the second edition of his "Einleitung in die Philosophie" he speaks about "the idea of an inductive metaphysics, growing out of the other sciences and complementing them" (Külpe 21898, 25; our translation). ${ }^{7}$

It is important to note that the early advocates of inductive metaphysics shared two basic convictions: (1) metaphysics is an indispensable philosophical discipline, perhaps even the core of philosophy in general; and (2) the empirical sciences, due to their inductive methodology, do not produce apodictic certainties, but only fallible knowledge. However, in contrast to a priori metaphysics, which according to these early advocates produced only pseudoknowledge, the empirical sciences generate real knowledge. Therefore, they concluded, it is the inductive methodology of the empirical sciences that should be used as a model for metaphysics.

The inductive metaphysicians also characterised metaphysics as indispensable, because only metaphysics enables an all-encompassing view of the world, in contrast to the particular sciences, which allow us only to look at particular parts or aspects of the world. While the basic idea of the inductive metaphysicians was therefore to pursue metaphysics with the approved methodology of natural science, the object of metaphysics was considered to be that of an "all-encompassing reality" (cf. Wundt 1883, 619; Külpe 1912, 194; and Becher 1926, 5 f.). For example, Becher claimed in this respect that "metaphysics as 'total science', the science of the overall reality, is by no means a mere

6 "Nur die allgemeine Bemerkung mag mir hier erlaubt sein, dass ich die Metaphysik weder für eine 'Begriffsdichtung' noch auch für ein mittelst specifischer Methoden aus a priori gültigen Voraussetzungen zu construierendes Vernunftsystem halte, sondern dass mir als die Grundlage derselben die Erfahrung, als ihre allein zulässige Methode die schon in den Einzelwissenschaften überall angewandte Verbindung der Tathsachen nach dem Princip von Grund und Folge gilt. Ihre eigentümliche Aufgabe erblicke ich aber darin, dass sie jene Verbindung nicht auf bestimmte Erfahrungsgebiete beschränkt, sondern auf die Gesammtheit aller gegebenen Erfahrung auszudehnen strebt." (Wundt 1889, vf.)

7 The whole passage reads: "Aber Kant war im Irrtum, wenn er meinte, Metaphysik wäre nur als Wissenschaft a priori, aus reiner Vernunft denkbar und würde hinfällig, sobald ein solches Verfahren als fruchtlos und angreifbar blossgestellt wäre. Die Idee einer inductiven, aus den übrigen Wissenschaften hervorwachsenden, sie ergänzenden Metaphysik hat weder ihm als eine Möglichkeit vorgeschwebt, noch durch seine Kritik irgendwie berührt werden können. Nur um eine solche kann es sich aber nach unserer Ansicht bei dem Aufbau einer wissenschaftlich begründeten Weltanschauung handeln, und es wäre nicht sonderlich schwer zu zeigen, dass auch die ältere Metaphysik trotz der scheinbaren Apriorität ihrer Methode stets unwillkürlich auf das Wissen ihrer Zeit Rücksicht genommen habe." (Külpe 21898, 25) 
compilation of the findings of the partial real sciences, the humanities and the natural sciences, which investigate the partial areas of reality" (Becher 1926, 5; our translation). ${ }^{8}$

In general, one can observe that among the early inductive metaphysicians inductive metaphysics appears on the one hand as a deflationary project, as an attempt to defend metaphysics with a moderate claim of justification against the scepticism of a Kantian type, but on the other hand also as an emphatic redefinition or even revival of the traditional fundamental idea of metaphysics.

The movement of inductive metaphysics was largely forgotten after Erich Becher's death in 1929. However, there is no need to consider it as a lost tradition. Just as the early advocates of inductive metaphysics did not consider the main idea of this approach to be limited to a small epoch within the range of the late 19th and early 2oth century - they were convinced that, in fact, metaphysicians had silently but consistently made use of elements of inductive metaphysics, at least in part, in all periods of the history of metaphysics this volume also aims to show that inductive metaphysical theorising plays an important role both in metaphysics before the 19th century and also in contemporary metaphysics.

\subsection{Sources of Knowledge in Inductive Metaphysics}

Not only empirical data but also findings derived from empirical data such as accepted and approved laws of nature, well-confirmed scientific hypotheses and theories or even scientific practice can be an essential basis for theory formation in inductive metaphysics. While outer experience (sense-experience, observation or measurement of objects in space-time) is clearly relevant, not all accounts of inductive metaphysics rely on inner experience (that is experience of cognitive processes or states and their content) or everyday life experience as well. If inner experience is taken into account, it must satisfy criteria of objectivity such as describability by empirical psychology and the metaphysical theories based on it must be explicitly related to principles of human cognition. Objectivity criteria for everyday experience may stem from relevant sciences or experimental philosophy.

Similar to data in science, experience plays two important roles in inductive metaphysics: First, it serves as the basis for hypothesis formation. Second, experience can also be used to confirm or disconfirm metaphysical hypotheses.

8 "Die Metaphysik als 'Totalwissenschaft', als Wissenschaft vom Gesamtwirklichen, ist keineswegs eine bloße Zusammenstellung der Erkenntnisse der Partialrealwissenschaften, der Geistes- und Naturwissenschaften, welche die Teilgebiete der Wirklichkeit erforschen." (Becher 1926, 5) 
To confirm a metaphysical hypothesis, it has to be guaranteed - as is the case in natural science when it comes to the confirmation of theoretical hypotheses containing 'latent' (unobservable) parameters or variables - that the data used for confirmation have not been used to construct the hypothesis in question (in philosophy of science this is known as the "use novelty criterion" - cf. Worrall 2006).

Even if inductive metaphysics, at least in part, uses the same data as that employed in the empirical sciences, namely certain natural phenomena, the question arises whether there is not also specifically metaphysical data. Inductive metaphysics aims, for example, at explaining scientific theories, accepted laws of nature, and hypotheses. Metaphysics differs from the particular sciences because it is not concerned with explaining natural phenomena of a certain type by laws of nature, but rather with tackling issues such as the question of what laws of nature are. Are they, for example, mere regularities, are they nomic relations in nature giving rise to such regularities, or do they result from the interaction of more fundamental dispositional properties?

Whatever way these questions are answered, it is clear that this contrast points at a difference in the sources of knowledge of metaphysics and natural science: Inductive metaphysics makes far less use of particular measurement data than of accepted laws of nature, hypotheses, and theories of the empirical sciences. Thus, if it is not based on everyday experience, the data stock of the metaphysician actually consists of meta-data; furthermore, it is blatantly smaller than that of the scientist working in a particular field of science. This raises the question of how inductive metaphysics should deal with the problem that a metaphysical hypothesis cannot be adapted to all its data and that there are, e.g., laws of nature that cannot be explained by the theory or even contradict it. In natural science, having particular outliers is the standard case in curve-fitting, and usually this is not considered to be a severe problem; in metaphysics, however, this problem seems to be extremely serious. For then either it must be assumed that the law of nature that is not explained by a metaphysical theory differs in a relevant sense from the explainable ones and that for this reason it is not in need of being explained by a metaphysical theory at all, or that it can be assumed that it is ultimately not a real law of nature.

\subsection{The Methodology of Inductive Metaphysics}

Inductive methods in the wide sense, that is any form of ampliative/nondeductive reasoning (cf. Schurz 2021, sect.1), play a constitutive role for inductive metaphysics. The most important non-deductive form of inference in science is abductive reasoning - besides inductive methods in the narrow sense such as enumerative induction and frequentist and statistical reasoning 
in general. Abductive reasoning comes in two forms (cf. Douven 2017, sect.1; Schurz 2008): There is explanatory reasoning in generating hypotheses or socalled creative abduction, which is about the abduction of theoretical hypotheses that contain new concepts or models on the basis of empirical data. And there is explanatory reasoning in justifying hypotheses or so-called selective abduction, which is about the selection among a set of such hypotheses and potential explanations. Often both forms of abductive inference are used in the form of a cascade: by the help of different applications (at different times and based on different data and background theories) of creative abduction, a set of alternatives is generated; and by the help of selective abduction the best among these is chosen.

Clearly, creative abduction is ampliative in the sense that the truth of the premises can never guarantee the truth of a new conclusion. However, creative abduction differs from other ampliative inferences such as induction in the narrow sense insofar as the latter is about generalisations on the basis of concepts and notions used in the premises, whereas the former also introduces new concepts and notions not used already in the premises (cf. Schurz 2008, 202). The prototype case of creative abduction is that of common cause reasoning: in science, a finding about an empirical correlation between two events gives rise to the inference that either one of the events caused the other or that both events are caused by another (new) event, a so-called common cause. The latter inference was spelt out in detail as so-called "common cause abduction" but can be generalised also to non-causal interpretations (for common cause abduction cf. Schurz 2008; for a generalisation to probabilistic contexts, see Feldbacher-Escamilla \& Gebharter 2019; for a discussion of alternative ways of causal search cf. Glymour 2019, sect.4). Creative abduction is employed in all sciences. Investigating general features of such reasoning as, for example, that of the involved notion of "causation", is what makes metaphysics based on the abductive methodology a trans-disciplinary approach accounting for most general notions of science. In this vein, some philosophers argue that causation is a genuinely metaphysical concept rather than a concept belonging to a particular scientific theory or discipline (cf. Schurz \& Gebharter 2016, Gebharter 2017, Schurz 2021, sect.7; Schurz 2021, sect.1, claims, for example, that the notion of a force belongs to physics, whereas the more general notion of a cause belongs to metaphysics; conservation laws belong to physics, whereas the principles of causality belong to metaphysics etc.).

Creative abduction can be grounded in (generalised) principles of causal reasoning and its theoretical relevance can be spelt out in terms of unificatory power (for details cf. Schurz 2008 and Feldbacher-Escamilla \& Gebharter 2019). However, causal reasoning and generalised causal principles are not 
exhaustive for justifying creative abductions. The reason for this is that common cause reasoning is basically too unspecific about the exact form of an inferred cause or common origin. Common cause reasoning allows one to infer only that a correlation between two events is due to some common cause - it is about the existence of such a cause - but details of the cause are left open. For this reason, also other criteria and virtues such as explanatory, predictive, and unificatory power have to be stressed in order to justify proper creative abductions in contrast to mere speculative forms of reasoning, so-called "speculative abductions" (cf. Schurz 2008, sect.7.1).

The theory of abduction traces back to Charles S. Peirce who was the first to explicitly distinguish between deduction, induction, and abduction. According to Peirce, the general schema of an abductive inference is as follows (cf. Peirce 1994, CP 5.189):

1. The surprising fact, $E$, is observed.

2. $\quad$ But if $H$ were true, $E$ would be a matter of course.

3. Hence, there is reason to suspect that $H$ is true.

According to this schema, abduction is an inference to a hypothesis (or theoretical statement or explanatory statement). However, since different and even conflicting hypotheses can account for one and the same evidence, the Peircean schema is best understood in its comparative form, stating that if a surprising fact is better accounted for by the help of one hypothesis rather than another, then one has reason to suspect that also the respective hypothesis is true rather than the other. If the abductive conclusion about hypotheses $H$ does not introduce new concepts or models, but relies on scientific laws that are already independently confirmed, then typically a large body of potentially explaining hypotheses are available. In this case, the Peircean schema of abduction transforms into a schema of selective abduction, and since it is about selecting among a set of explanatory hypotheses, it can also be characterised as an inference to the best explanation, also "IBE". (IBE was made prominent particularly by Lipton 1991/2004. The term "inference to the best explanation" was coined by Harman 1965.)

An IBE allows one to infer that the explanans of an explanation explaining some fact is true if it best fulfils certain criteria relevant for explanation. This comparison consists of a trade-off between several (empirical and theoretical) explanatory virtues. Explanatory virtues are, amongst others, the accuracy of an explanation in terms of fit with the data but also simplicity and explanatory strength. Of particular importance for metaphysics is, for example, that the virtue of simplicity has several feasible interpretations: it can be about simplicity in terms of the number of entities, properties or relations; it can be about the number of different kinds of such entities; it can be about the number of 
principles used in an explanation; it can be about the number of parameters in models, etc. (for various notions of simplicity cf. Sober 2015). But not only in this respect there is a lot of variability in spelling out the methodology. Also, these virtues can come into conflict with each other: an explanation might fulfil the simplicity criterion to a very high degree, but does less well in fitting the data, whereas a competing explanation might be less simple and fit the data better. The fulfilment of the criteria must therefore be weighed against each other (cf. Schurz 2008). Up to now, the criteria for doing so are far from clear, especially because IBE can be applied not only to isolated explanations but also to whole theories.

IBE is extensively used in contemporary metaphysics (cf. Swoyer 1983, 1999). Especially extreme forms of IBE seem to have a long tradition: an extreme form results, for example, if all competing explanations are discarded for some reason. In this case, one speaks of an "inference to the only explanation": IOE (cf. Bird 2007). Another even more extreme form results if there are no possible competitors at all. In this case, one speaks of an "inference to the only possible explanation": IOPE (cf. Feldbacher-Escamilla forthcoming-a, forthcoming-b). These forms of IBE are particularly important in the history of philosophy - at least in the rhetoric of many authors, like Christian Wolff or Kant in the form of transcendental arguments. A reason might be that they make up for monotonic inferences which align better to traditional approaches to metaphysical knowledge.

A good example of a metaphysician who follows the method of inductive metaphysics without explicitly subscribing to the term is Richard Corry. In his Power and Influence he describes his method as follows (Corry 2019, p. 42):

What I would have liked to have done here is produce a transcendental argument for the existence of causal influences. Such influences, I would like to say, are necessary presuppositions of one of the most useful and successful (and I might suggest essential) methods we have for understanding the world [i.e. the reductive method]. The difficulty is of course providing necessity. [...] But if I am right that causal influences are assumed by the reductive method, then the spectacular success of this method gives us good reason to believe in them. We shall see through the rest of this book, that an ontology that includes causal influences and causal powers can do more than simply ground the reductive method. Influences can help us solve problems in understanding laws of nature, causation, the possibility of emergent properties, and maybe even ethics. 
Corry's method follows exactly the scheme of inductive metaphysics: through creative abduction in the form of an IOPE, first, the existence of an explanatory entity is inferred. Afterwards, the hypothesis is strengthened by hinting at the explanatory power gained by such a strengthening.

Abductive reasoning is essential for inductive metaphysics. Another core method of inductive metaphysics is conceptual analysis, although conceptual analysis is (traditionally considered to be) a priori. Despite the aprioricity of conceptual analysis, inductive metaphysics acknowledges it as an important and even necessary, though not sufficient tool of metaphysical investigation. Particularly as an intermediate step within such investigations it is broadly accepted.

\subsection{Meta-Metaphysical Issues in the Light of Inductive Metaphysics}

The approach of inductive metaphysics gives rise to a number of open issues and questions about the concept of metaphysics as a whole, but also about its methodology.

First, one important question that inductive metaphysics approaches is the question about the goal of metaphysical theories and their validity. Are they theories with an immediate claim to truth, or does metaphysics only provide explanatory models whose usefulness, adequacy or truth can only be tested subsequently and possibly not at all with the help of metaphysical investigations themselves (cf. Jaag/Löw forthcoming)?

Second, another debate in this field is about the question of what kind of explanations metaphysical theories should provide: while natural science often provides causal explanations, metaphysics seems to be primarily concerned with grounding explanations, that is explanations that show by help of which entities and relations the respective data are to be grounded. Do laws of nature supervene, for example, on a mosaic of non-modal property instances in space-time or on nomic relations between property instances or on basic facts about modal properties, to mention only three of the many discussed alternatives in this field.

Third, if it turns out that metaphysical theories provide only models whose adequacy, applicability, and truth cannot be determined by help of metaphysical investigation itself, then the question arises as to which discipline is able to fulfil this task. Insofar as metaphysics is a trans-disciplinary approach, it is not clear which particular science could accomplish this.

Fourth, if one understands inductive metaphysics as a trans-disciplinary approach, a problem arises also for the practice of philosophising: already naturalised metaphysics faces the problem of a lack of competence. If metaphysical knowledge is to be derived from fundamental theories of scientific fields 
such as physics, it seems that a metaphysician must either be a physicist herself or work in extraordinarily close interdisciplinary cooperation with physicists. If, however, not only physics is relevant for metaphysics, but also several other disciplines, then the demand for the participating scientist increases drastically (for a general discussion of the problem of "Individuals Across the Sciences" cf. Guay \& Pradeu 2015). This problem becomes even more urgent if it turns out that metaphysical concepts are not only more abstract in gradual terms than those of the particular sciences, but also more abstract in qualitative terms that give them a proper metaphysical character.

Fifth, it is unclear which attitude inductive metaphysics takes towards the classical and still influential thought that metaphysics is concerned not only with the basic structure of the actual world, but also that of all other or at least the nomologically possible worlds. Since natural science itself requires at least a certain excerpt of the metaphysically possible, the question arises as to which discipline is responsible for determining what is metaphysically possible and what not. If it is not metaphysics which answers this question, what other discipline can do so? For example, is it logic? This raises serious questions regarding the relationship between logic and metaphysics which are currently quite controversially discussed (cf. Williamson 2013).

We think that the work of our research group on Inductive Metaphysics as well as the contributions in this volume prepare the ground for answering these and many other questions related to this topic. So, for example, new work on anti-exceptionalism in the philosophy of logic suggests that an abductive methodology is also fruitfully applied there (cf. Ferrari \& Moruzzi 2017). By this and many other investigations we hope that the programme of inductive metaphysics can be established as a fruitful and progressive research programme.

\section{The Contributions in the Special Issue}

This special issue comprises three kinds of contributions: First, contributions in which aspects of the methodology and the theoretical context of inductive metaphysics are studied (cf. Bryant 2021, Schurz 2021, and Simons 2021, this volume); second, contributions that are particularly about applying the approach of inductive metaphysics (cf. Busse 2021 and Tugby 2021, this volume); and third, contributions that focus on an historical investigation of inductive metaphysics (cf. Engelhard 2021, Pelletier 2021, and Seide 2021, this volume). In the remainder of this introduction, we will provide brief summaries of them. 
In her contribution "Epistemic Infrastructure for a Scientific Metaphysics", Amanda Bryant aims at providing a set of epistemic principles that should underlie metaphysical investigations. The principles discussed by her are to be distinguished from the epistemic infrastructure provided by naturalised metaphysics inasmuch as the latter is narrower and focusses on scientific evidence only, but not evidence in general. Her approach is also to be distinguished from the epistemic infrastructure provided by scientism which has much stronger aims and targets of inquiry that are more difficult to defend. According to Bryant's suggestion, the epistemic principles for the justification of theories are different modal and comparative qualifications of the claim that theories are epistemically adequate only if they are constrained in a suitably robust way. Constraints are suitably robust only if fulfilling them is instrumental to the aim of converging on a justified theory. Adhering to these principles has the merits that robustly constrained theories are (prima facie) likelier to be true, more conducive to agreement, more likely to exclude substantial falsities, and they better target relevant facts than their more complex rivals do. Bryant then instantiates this general discussion to scientific metaphysics by stressing that such a metaphysics inherits relatively robust constrains, because it introduces a scientific constraint on its theoretical content.

Gerhard Schurz' contribution "Abduction as a Method of Inductive Metaphysics" is about the methodology of inductive metaphysics and its application. First, Schurz stresses that inductive metaphysics relies on induction in the wide sense, that is a non-deductive methodology, particularly on abduction. Then he distinguishes two forms of abduction: creative abduction which introduces new notions; and selective abduction or inference to the best explanation which chooses among a set of alternative hypotheses (and by this does not introduce new notions). For inductive metaphysics of particular importance is creative abduction which can be justified by help of general principles of causal reasoning and which is based on two rationality conditions: unificatory power and independent testability (that is the capacity to make use-novel predictions). These rationality criteria are important because they rule out inferences to pseudo-explanations via trivial (so-called "tacking by conjunction") or speculative abductions (that is abductions introducing hidden/unobservable causes such as, for example, God's will or wishes, which do not contribute in providing a unified explanation or which cannot be confirmed independently). Having outlined the methodology of inductive metaphysics, Schurz discusses two metaphysical applications that satisfy the two rationality criteria: metaphysical realism and justifying causation. Regarding metaphysical realism, he argues that the inference of an external world ${ }_{3} \mathrm{D}$ objects) from our sensual experiences $(2 \mathrm{D}$ sensual data) is a creative abductive 
inference (stating ${ }_{3} \mathrm{D}$ objects and laws of perception in order to explain by help of common cause-reasoning correlations among the $2 \mathrm{D}$ sensual data) which is explanatory advantageous to alternative explanations such as the brain in a vat-hypothesis (the latter is less parsimonious than the former). Also, according to Schurz, such an abductive inference unifies the sensual data and allows for use-novel predictions as, for example, the prediction of correlations among data of different senses. Regarding the justification of causation, Schurz argues that two frequent statistical phenomena, namely screening off (two statistical events become independent conditional on a third statistical event) and linking up (two statistical events become dependent conditional on a third statistical event) are best explained by causal reasoning, which unifies the statistical phenomena and produces use-novel empirical content.

Peter Simons' contribution to this special issue has the beautifully metaphorical title "The Long and Winding Road: Folly and Feedback in Metaphysics". Simons introduces and discusses an extensive list of metaphysical follies and the kind of extreme positions to which these follies ultimately lead from a historical but also from a contemporary perspective. Follies are distinguished into two different types: Those which stand in stark contrast to common sense, and those which are directly opposed to the results of well-established empirical science. It becomes clear in the text how these follies blocked a straight and continuous convergence of analytic metaphysics towards science and that, because of this, one important way for metaphysics to progress consists in methodologically avoiding or reducing the risks of making such follies. Simons discusses some of the more prominent attempts to back up (or undermine) metaphysical positions by empirical results that can be found in the literature such as the experiments carried out by Benjamin Libet and his colleagues in the 1980s, which by many have been interpreted to undermine free will. Finally, Simons proposes strategies to reduce the threat of metaphysical follies. Here are some examples from his text how this could be done: Metaphysics should, for instance, "put forward a structure of ontological categories which aspire to universal coverage, while allowing that the categories be revisable" (Simons 2021, sec. 4), metaphysicians should be patient and wait for empirical evidence to become available instead of loosing themselves in a priori armchair speculations, and metaphysicians should always explicitly specify which parts of their metaphysics are speculative.

Ralf Busse's contribution "Against Metaphysical Structuralism" argues by help of a case study that a priori evaluations of metaphysical theories and in general traditional ways of metaphysical reasoning are essential for inductive metaphysics. In doing so, he employs a relatively liberal notion of the a priori, calling a philosophical investigation a priori if all the theoretic work 
is done when all the relevant scientific findings are prepared. A case in point showing that inductive metaphysics is in need of a priori elements is, according to Busse, the metaphysical discussion of structuralism which is motivated in opposition to particularism, the view that the fundamental level of reality contains only primitively individuated particulars. An approach within the framework of inductive metaphysics (but without or with too little a priori elements) is Dasgupta's algebraic generalism. Proceeding from results of empirical sciences, Dasgupta argues against particularism on the basis that in physics the individuality of particulars plays no role and that for this reason they should be abandoned also in metaphysics. This line of reasoning was criticised in the sense that structuralism is used to argue against pessimistic meta-induction, showing that although there is constant theory change, we can have knowledge, namely knowledge of something/structure that remains approximately constant. However, there is the problem that most fundamental notions of physics like that of mass and charge changed. In order to defend Dasgupta's account from this criticism, Busse suggests to distinguish between world structure, that is the (metaphysically) supposed structure of reality, and theoretic structure, that is the (physically and in general scientifically accessibly) supposed structure of reality. Whereas the latter changes, because we will never achieve a comprehensive picture of the world, the former remains constant and is what (Dasgupta's) structuralism of algebraic generalism should be about. Busse argues that the case study of structuralism shows that metaphysical theory building and theory assessment hinges essentially on a priori reasoning: a priori reasoning is necessary when one constructs a language for an "imaginable ideal being with perfect semantic and epistemic access to the complete fundament of reality" (that is a language of world structure), because such a language transcends the machineries constructed and employed in science (that is a language of theoretical structure).

In his article "Abduction and the Scientific Realist Case for Properties", Matthew Tugby investigates one of the most essential pieces in the inductive metaphysian's tool kit, abductive inference, on its usefulness for metaphysics, and on how it can ground metaphysics in science. In particular, he is interested in the abductive principle that one should believe "in the existence of an entity, or type of entity, if it figures in the best explanation for the observable phenomena" (Tugby, 2021, sec. 1) and in its application to the property realism debate. On the basis of that principle, Tugby argues that one should accept realism about theoretical properties if one subscribes to scientific entity realism. The latter is a view shared by many philosophers of science and philosophically minded scientists. In doing so, he adds a clearly more science-based argument to the already available more classical arguments for property realism which 
are typically based on conceptual analysis and a priori reasoning. This nicely shows what inductive metaphysics can add to a more traditional understanding of metaphysics as an a priori exercise. In addition to his general argument, Tugby also considers several possible objections and how they could be countered. He discusses, for example, the possible worry that scientific properties are often quantitative, while the property realist's properties are classically qualitative. Another possible worry addressed in the article is whether different versions of nominalism could not provide better explanations for the behavioural patterns studied by science than property realism does.

In her article "Methods and Roles of Experience in Christian Wolff's 'Deutsche Metaphysik", Kristina Engelhard explores whether Kant's concept of metaphysics can be taken as an adequate description of the discipline of his time. She argues that this is not the case, since in his "Deutsche Metaphysik", Christian Wolff makes extensive use of the inductive methodology and experiential facts serve several foundational roles. Her conclusions therefore underline research results of recent years which show that Wolff's philosophy is strongly experiential. In a first step of her investigation, she examines Wolff's concept of experience. He distinguishes ordinary experience from experience in scientific experimentation. Experience can be used for formation of hypotheses or for their confirmation. According to Wolff, empirical knowledge is inferential and is composed of several factors. Engelhard disentangles those factors that are, according to Wolff, relevant for the formation of empirical knowledge in both cases, in ordinary and scientific experience. Experiencing something as something involves knowledge of the essential dispositions of the object of experience and enables predictions of its future behaviour. Most notably, Wolff establishes and follows what Engelhard calls the "fundamental factuality principle", which says that experiential or phenomenal facts can be taken to be foundational for explanatory purposes even if they are not explained themselves. In the second step, she investigates experiential sources of metaphysical knowledge that can take the form of inner and outer experience, that is experience of one's own cognitive states and experiences of outer objects in space-time. An important point for Wolff's inductive reasoning in his "Deutsche Metaphysik" is his version of the Cartesian first certainty: according to Engelhard's reading, Wolff holds that the truth of this certainty is secured by inner self-experience. This truth is the foundation of all of Wolff's "Deutsche Metaphysik". However, he also derives metaphysical hypotheses from scientific findings of his time. In the next step, Engelhard shows examples of inductive inferences in Wolff's "Deutsche Metaphysik"; she analyses a creative abduction which is supposed to show that all bodies have an immanent moving power from the phenomenon of motion. Wolff excludes two seeming alternative 
explanations. Hence, his argument takes the form of an inference to the only possible explanation. A final consideration of Engelhard's article concerns the relation between abduction and the principle of sufficient reason so prominently held by Wolff in his metaphysics. Engelhard claims that abduction is the formal counterpart of the metaphysical principle of sufficient reason which is a metaphysical thesis about the constitution of the world. In the cases Engelhard discusses, Wolff does not need to implement any metaphysical warrant for his reasoning, hence, it is enough to take his arguments to be abductions.

The goal of Arnaud Pelletier's article "Leibniz's Inductive Challenge: First Experiences and the Metaphysics of Monads" is a detailed analysis of the opening paragraphs of Leibniz' "Monadology". Contrary to the common rationalist interpretation of Leibniz' philosophy, Pelletier argues in the last two parts of his article (Pelletier, 2021) that these passages, which aim to show that "there are composites" and that "there are substances", should not be understood as a deductive inference but as an inference from experiential evidence. In particular, it is about what Leibniz calls "first experiences", namely the experience that "I think" and the experience that "a variety of things are always thought by me". This foundational inductive element in Leibniz has probably been overlooked for so long because Leibniz explicitly dismisses induction as a method in metaphysics. However, Pelletier shows in the first part of his article that Leibniz differentiates between two kinds of induction. He dismisses enumerative induction - which is called "epistemic induction" by Pelletier as a method of metaphysics. Pelletier shows that Leibniz dismisses epistemic induction because of the inferior certainty of its conclusion. But Leibniz also discusses induction as a method of grasping the first principles of any demonstrated doctrine, which Pelletier calls "metaphysical induction". Now, the decisive questions for the thesis of the article are first, how does Leibniz' explicit dogma that all metaphysical truths must have demonstrative warrant relate to the assumption that there are "first experiences", and second, whether experiential evidence really plays a constitutive role in Leibniz' metaphysics. Pelletier claims that the "first experiences" are a case of constitutive experiential evidence in the late Leibniz and that this is not contrary to his dogma of the demonstrative character of metaphysics. In the second part of his article, Pelletier therefore discusses Leibniz' conception of demonstration in metaphysics, points out what first experiences are and how they can play a constitutive role in metaphysics within the Leibnizian framework. Most interestingly, Leibniz as early as in 1685 thinks that there are first principles that are true not because they serve as first premises in deductive inferences in the sense that all truths follow from them more or less directly, but rather that there are first principles which are warranted because they are necessary conditions 
for demonstrations. Of this kind are the first experiences. They are necessary conditions of demonstrations to be possible. In this sense, Pelletier shows that a rationalist view of Leibniz' metaphysics is at least incomprehensive and that inductive elements are constitutive at least in his late metaphysics.

In his article "Analogical Inference in Gustav Theodor Fechner's Inductive Metaphysics", Ansgar Seide investigates the approach to inductive metaphysics by Gustav Theodor Fechner, one of the founding fathers of the programme of inductive metaphysics in the mid-19th century. The main method of Fechner's inductive metaphysics is analogical reasoning. The focus of Seide's investigation is an analogical argument which is central to Fechner's cosmological view as presented in his book Zend-Avesta oder über die Dinge des Himmels und des Jenseits, an argument to the conclusion that the earth has a soul. By investigating the details of this exemplary argument, Seide also aims to shed light on the principle of analogical inference in the background of Fechner's approach. Broadly speaking, Fechner argues that the earth is similar to the body of human beings in certain relevant respects and then infers from this that the earth, analogous to human beings, has a soul. In his evaluation of this inference, Seide draws upon criteria for good analogical arguments as brought forward by Mary Hesse. In particular, Hesse argues that for an analogical inference to be correct, the properties of each analogue must be causally related in the right way. Applied to the case of Fechner's inference this means that for the inference to be correct there must be a causal connection between certain aspects of the human body and the human soul, which is transferable to the case of the earth: it must be plausible to assume that there is an analogous causal connection between the aspects of the earth known to be similar to parts of the human body and an alleged soul of the earth. While it might seem plausible that there is a causal connection (at least in a broad sense) between certain parts of the human body and the human soul, it turns out that Fechner's analogy between the human body and the earth is based on similarities that are not related to this causal connection. In particular, we may consider certain characteristics concerning the organisation of the human nervous system to be causally relevant for the human soul, but the similarities between the human body and the earth Fechner puts forward do not concern these particular aspects. Seide concludes that Fechner's argument for the claim that the earth has a soul fails because the analogical inference at the centre of the argument does not meet Hesse's causal criterion for good analogical inferences. However, as he points out, this must not be seen as a negative verdict on the idea of inductive metaphysics in general, but as an insight into the criteria that analogical inferences must meet in order to be successfully used in inductive metaphysics. 


\section{Acknowledgments}

We would like to thank the members of the research group Inductive Metaphysics and the participants of the workshop Traditional and Inductive Metaphysics, December 7-8, 2017, Tu Dortmund University, for valuable feedback on this topic. This work was supported by the DFG (Deutsche Forschungsgemeinschaft) funded research group Inductive Metaphysics (FOR 2495).

\section{References}

Becher, Erich 1926. Metaphysik und Naturwissenschaften. Eine wissenschaftstheoretische Untersuchung ihres Verhältnisses. München \& Leipzig: Duncker \& Humblot.

Bird, Alexander 2007. "Inference to the Only Explanation." Philosophy and Phenomenological Research LXXIV(2), 424-432.

Braddon, David \& Nola, Robert (eds.) 2009. Conceptual Analysis and Philosophical Naturalism. Cambridge/Mass.: MIT Press.

Bryant, Amanda 2021. "Epistemic Infrastructure for a Scientific Metaphysics". Grazer Philosophische Studien 98(1), 27-49, this volume.

Busse, Ralf 2021. "Against Metaphysical Structuralism. A Case Study on the Apriori Dimension within Inductive Metaphysics". Grazer Philosophische Studien 98(1), 90-122, this volume.

Corry, Richard 2019. Power and Influence. The Metaphysics of Reductive Explanation. Oxford: Oxford University Press.

Dasgupta, Shamik 2009. "Individuals: An Essay in Revisionary Metaphysics." Philosophical Studies 145(1), 35-67.

Douven, Igor 2017. "Abduction." In: The Stanford Encyclopedia of Philosophy (Summer 2017 Edition). Edited by Edward N. Zalta. URL $=<$ https://plato.stanford.edu/ archives/sum2017/entries/abduction/>.

Engelhard, Kristina 2021. "Methods and Roles of Experience in Christian Wolff's "Deutsche Metaphysik"'. Grazer Philosophische Studien 98(1), 146-166, this volume. Fechner, Gustav Theodor 1851. Zend-Avesta oder über die Dinge des Himmels und des Jenseits. Vom Standpunkt der Naturbetrachtung. Drei Theile. Leipzig: Leopold Voß.

Feldbacher-Escamilla, Christian J. forthcoming-a. "Apagogic Proof and Kant's Transcendental Reasoning."

Feldbacher-Escamilla, Christian J. forthcoming-b. "Transcendental Reasoning and Abduction." 
Feldbacher-Escamilla, Christian J. \& Gebharter, Alexander 2019. "Modeling Creative Abduction Bayesian Style." European Journal for Philosophy of Science 9(1), 1-15. DOI: 10.1007/s13194-018-0234-4.

Ferrari, Filippo \& Moruzzi, Sebastiano 2017. "Logical Pluralism, Indeterminacy and the Normativity of Logic." Inquiry 63(3-4), 323-364. DOI: 10.1080/0020174X.2017 .1393198 .

Fine, Kit 2012. "What is metaphysics?" In: Contemporary Aristotelian Metaphysics. Edited by Tuomas Tahko, Cambridge: Cambridge University Press, 8-25.

Gebharter, Alexander 2017. Causal nets, interventionism, and mechanisms. Cham: Springer. DOI: 10.1007/978-3-319-49908-6.

Glymour, Clark 2019. "Creative Abduction, Factor Analysis, and the Causes of Liberal Democracy." KRITERION - Journal of Philosophy 33(1), 1-22.

Guay, Alexandre \& Pradeu, Thomas 2015. Individuals Across the Sciences. Oxford: Oxford University Press.

Harman, Gilbert 1965. "The Inference to the Best Explanation." The Philosophical Review 74(1), 88-95.

Jaag, Siegfried \& Löw, Christian forthcoming. "Why Defend Humean Supervenience?” The Journal of Philosophy.

Kant, Immanuel 1998. Critique of Pure Reason. Edited and translated by Paul Guyer and Allen W. Wood, Cambridge: Cambridge Universkakatuwanity Press.

Kant, Immanuel 2002. Theoretical Philosophy after 1781. Edited by Henry Allison \& Peter Heath, translated by Gary Hatfield, Michael Friedman, Henry Allison \& Peter Heath, Cambridge: Cambridge University Press.

Kincaid, Harold 2013. "Introduction: Pursuing a Naturalist Metaphysics". In: Scientific Metaphysics. Edited by Don Ross, James Ladyman \& Harold Kincaid. Oxford: Oxford University Press, 1-26.

Külpe, Oswald1912.DieRealisierung. Ein Beitragzur Grundlegung derRealwissenschaften. Erster Band. Leipzig: S. Hirzel.

Külpe, Oswald ${ }^{2}$ 1898. Einleitung in die Philosophie. Leipzig: Hirzel.

Ladyman, James \& Ross, Don 2007. Every Thing Must Go. Metaphysics Naturalized. Oxford: Oxford University Press.

Lipton, Peter 1991. Inference to the Best Explanation, London: Routledge.

Lipton, Peter ${ }^{2} 2004$. Inference to the Best Explanation. 2nd revised ed., London: Routledge.

Lotze, Rudolph Hermann 1899. Microcosmus. An Essay Concerning Man and His Relation to the World, trans. by Elizabeth Hamilton \& E. E. Constance Jones, 2 volumes, Edinburgh: T. \& T. Clark, 1885; 4th edition, 1899. (German original: Mikrokosmus. Ideen zur Naturgeschichte und Geschichte der Menschheit. 1856 (vol. I), $185^{8}$ (vol. II), 1864 (vol. III). Leipzig: S. Hirzel.) 
Lowe, E. J. 2001. The Possibility of Metaphysics. Oxford: Oxford University Press. Maudlin, Tim 2007. The Metaphysics within Physics. Oxford: Oxford University Press. Mohammadian, Mousa 2019. "Abduction: The Context of Discovery + Underdetermination = Inference to the Best Explanation." Synthese. DoI: 10.1007/ s11229-019-02337-z.

Niiniluoto, Ilkka 2018. Truth-Seeking by Abduction. Dordrecht: Springer.

Paul, L. A. 2012. "Metaphysics as Modeling. The Handmaiden's Tale." Philosophical Studies 16o(1), 1-29.

Peirce, Charles Sanders 1994. Collected Papers of Charles Sanders Peirce. Edited by Charles Hartshorne, Paul Weiss \& Arthur W. Burks, Harvard: Harvard University Press.

Pelletier, Arnaud 2021. "Leibniz's Inductive Challenge: First experiences and the metaphysics of monads". Grazer Philosophische Studien 98(1), 167-185, this volume.

Reale, Giovanni 1980. The Concept of First Philosophy and the Unity of the Metaphysics of Aristotle. Edited and translated by John R. Catan. Albany: suny Press.

Schaffer, Jonathan 2016. "It is the Business of Laws to Govern." Dialectica 70 (4), 577-588. Scholz, Oliver R. 2018. "Induktive Metaphysik. Ein vergessenes Kapitel der Metaphysikgeschichte." In: Philosophische Sprache zwischen Tradition und Innovation. Edited by David Hommen \& Dennis Sölch, Frankfurt am Main: Peter Lang, 267-289.

Schupbach, Jonah N. 2017. "Inference to the Best Explanation, Cleaned Up and Made Respectable." In: Best Explanations: New Essays on Inference to the Best Explanation. Edited by Kevin McCain \& Ted Posten, Oxford: Oxford University Press, 39-61.

Schurz, Gerhard 2008. "Patterns of Abduction." Synthese 164, 201-234.

Schurz, Gerhard \& Gebharter, Alexander 2016. Causality as a theoretical concept: Explanatory warrant and empirical content of the theory of causal nets. Synthese 193(4), 1073-1103. DOI: 10.1007/s11229-014-0630-Z.

Schurz, Gerhard 2021. "Abduction as a Method of Inductive Metaphysics". Grazer Philosophische Studien 98(1), 50-74, this volume.

Seide, Ansgar 2020. Die Notwendigkeit empirischer Naturgesetze bei Kant. De Gruyter: Berlin \& Boston.

Seide, Ansgar forthcoming-a. "The Relation Between Empirical and a priori Elements in Kant's Special Metaphysics of Nature."

Seide, Ansgar forthcoming-b. "Wilhelm Wundts Logik als Auftakt zu einer induktiven Metaphysik."

Seide, Ansgar 2021. "Analogical Inference in Gustav Theodor Fechner's Inductive Metaphysics". Grazer Philosophische Studien 98(1), 186-202, this volume.

Simons, Peter 2021. "The Long and Winding Road: Folly and Feedback in Metaphysics". Grazer Philosophische Studien 98(1), 75-89, this volume. 
Sober, Elliott 2015. Ockham's Razors. A User's Manual. Cambridge: Cambridge University Press.

Swoyer, Chris 1983. "Realism and Explanation." Philosophical Inquiry 5, 14-28.

Swoyer, Chris 1999. "How Ontology Might be Possible: Explanation and Inference in Metaphysics.” Midwest Studies in Philosophy xxıII, 100-131.

Tugby, Matthew 2021. "Abduction and the Scientific Realist Case for Properties". Grazer Philosophische Studien 98(1), 123-145, this volume.

Williamson, Timothy 2013. Modal Logic as Metaphysics. Oxford: Oxford University Press.

Worrall, John 2006. "Theory-Confirmation and History." In: Rationality and Reality. Conversations with Alan Musgrave. Edited by Colin Cheyne \& John Worall, Dordrecht: Springer, 31-61.

Wundt, Wilhelm 1883. Logik-Eine Untersuchung der Principien der Erkenntniss und der Methoden wissenschaftlicher Forschung. Zweiter Band: Methodenlehre. Stuttgart: Ferdinand Enke.

Wundt, Wilhelm 1889. System der Philosophie. Leipzig: Wilhelm Engelmann. 